\title{
Optogenetic Stimulation of Locus Ceruleus Neurons Augments Inhibitory Transmission to Parasympathetic Cardiac Vagal Neurons via Activation of Brainstem $\alpha 1$ and $\beta 1$ Receptors
}

\author{
Xin Wang, Ramón A. Piñol, Peter Byrne, and David Mendelowitz \\ Department of Pharmacology and Physiology, Department of Anesthesiology and Critical Care Medicine, The George Washington University, Washington, \\ District of Columbia 20037
}

Locus ceruleus (LC) noradrenergic neurons are critical in generating alertness. In addition to inducing cortical arousal, the LC also orchestrates changes in accompanying autonomic system function that compliments increased attention, such as during stress, excitation, and/or exposure to averse or novel stimuli. Although the association between arousal and increased heart rate is well accepted, the neurobiological link between the LC and parasympathetic neurons that control heart rate has not been identified. In this study, we test directly whether activation of noradrenergic neurons in the LC influences brainstem parasympathetic cardiac vagal neurons (CVNs). CVNs were identified in transgenic mice that express channel-rhodopsin-2 (ChR2) in LC tyrosine hydroxylase neurons. Photoactivation evoked a rapid depolarization, increased firing, and excitatory inward currents in ChR2-expressing neurons in the LC. Photostimulation of LC neurons did not alter excitatory currents, but increased inhibitory neurotransmission to CVNs. Optogenetic activation of LC neurons increased the frequency of isolated glycinergic IPSCs by $27 \pm 8 \%(p=0.003, n=26)$ and augmented GABAergic IPSCs in CVNs by $21 \pm 5 \%(p=0.001, n=26)$. Inhibiting $\alpha 1$, but not $\alpha 2$, receptors blocked the evoked responses. Inhibiting $\beta 1$ receptors prevented the increase in glycinergic, but not GABAergic, IPSCs in CVNs. This study demonstrates LC noradrenergic neurons inhibit the brainstem CVNs that generate parasympathetic activity to the heart. This inhibition of CVNs would increase heart rate and risks associated with tachycardia. The receptors activated within this pathway, $\alpha 1$ and/or $\beta 1$ receptors, are targets for clinically prescribed antagonists that promote slower, cardioprotective heart rates during heightened vigilant states.

Key words: cardiac vagal neurons; locus ceruleus; optogenetic stimulation

\section{Introduction}

Stress, wakefulness, and attention each evoke increases in heart rate. A state of high vigilance is associated with tachycardia and increased risk of arrhythmias, whereas sleep, and particularly nonrapid eye movement (non-REM) sleep, is associated with a stable pattern of reduced heart rate and a high level of parasympathetic activity to the heart (Toscani et al., 1996; Verrier et al., 1998). Neurons in the locus ceruleus (LC), also known as the A6 noradrenergic cell group, are critical in generating alertness, arousal, and emotional responses. LC neurons fire slowly during slow-wave sleep and can be nearly silent during REM sleep. LC neurons increase their firing with vigilance and arousal. Slow

\footnotetext{
Received Dec. 5, 2013; revised March 21, 2014; accepted March 24, 2014.

Author contributions:X.W., R.A.P., and D.M. designed research;X.W. and P.B. performed research;X.W. analyzed data; X.W., R.A.P., and D.M. wrote the paper.

This work was supported by the National Institutes of Health (Grants HL49965, HL59895, and HL72006 to D.M.). The authors declare no competing financial interests.

Correspondence should be addressed to David Mendelowitz, Department of Pharmacology and Physiology, Department of Anesthesiology and Critical Care Medicine, The George Washington University, 2300 Eye Street, NW, Washington, DC 20037. E-mail: dmendel@gwu.edu.

DOI:10.1523/JNEUROSCI.5093-13.2014

Copyright $\odot 2014$ the authors $\quad 0270-6474 / 14 / 346182-08 \$ 15.00 / 0$
}

irregular firing during quiet wakefulness increases to sustained higher frequencies of firing during stress, excitation, and/or exposure to averse or novel stimuli (España and Scammell, 2011).

The LC has norepinephrine synaptic contacts with many areas in the CNS (Goldstein et al., 1971; Olson and Fuxe, 1971; Nygren and Olson, 1977; Aston-Jones and Cohen, 2005b). It is possible that the LC, in addition to directly inducing cortical arousal, is capable of orchestrating changes in autonomic function during changes in arousal and attention.

Neural control of the heart is predominantly regulated by the parasympathetic division of the autonomic nervous system. Cardioinhibitory parasympathetic activity to the heart arises from the preganglionic cardiac vagal neurons (CVNs) located in the nucleus ambiguus (NA), dorsal motor nucleus of the vagus, and intermediate zone of the medulla oblongata (Standish et al., 1995; Cheng et al., 1999; Cheng and Powley, 2000). Vagal efferent axons from these cell bodies terminate upon the postganglionic intracardiac ganglia neurons located near the sinoatrial and atrioventricular nodes of the heart (Armour, 2008). Resting heart rate is regulated by tonic, parasympathetic vagal outflow from CVNs and CVNs exhibit tonic firing activity that is cardiac pulse syn- 

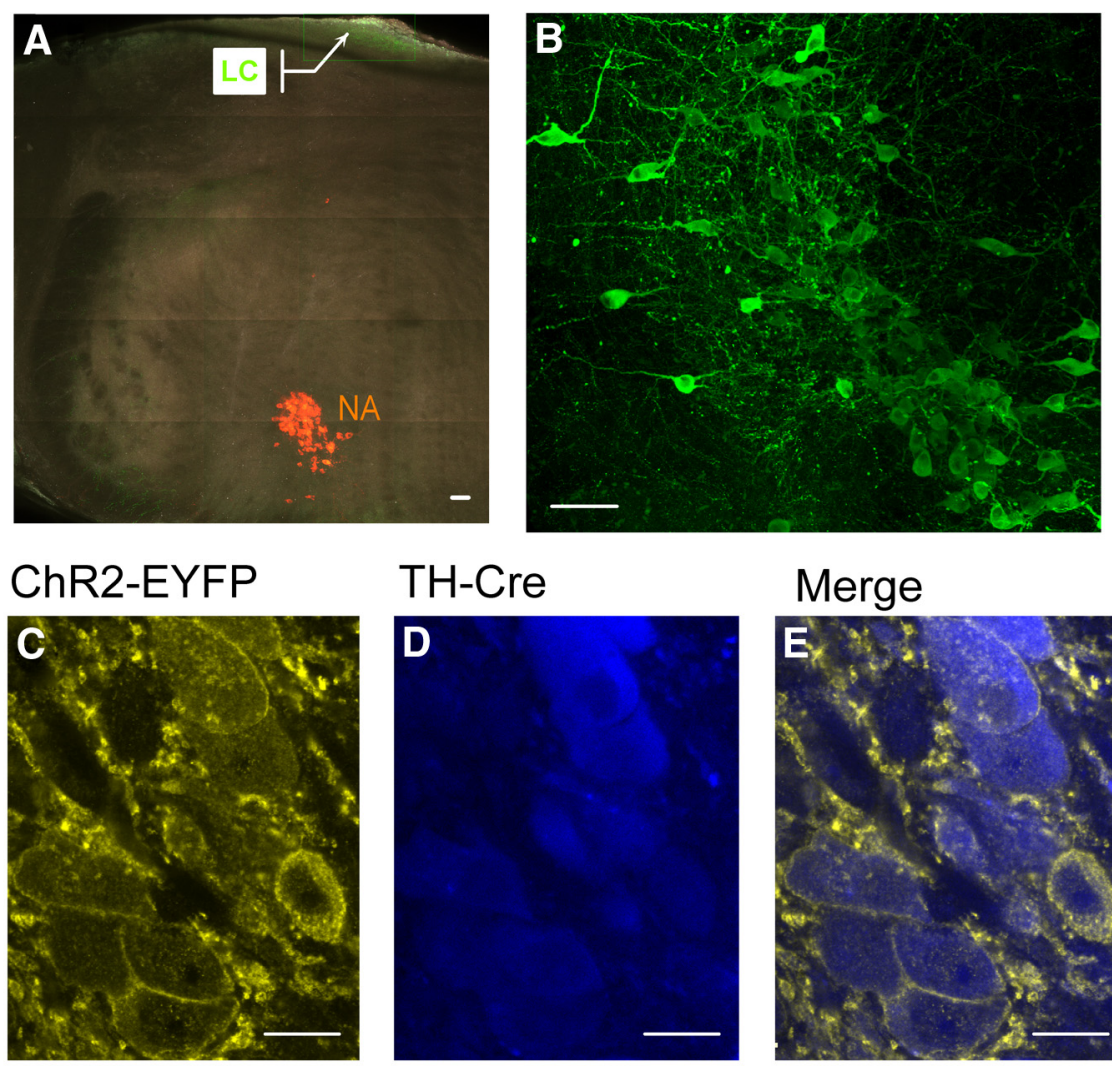

\section{Merge}

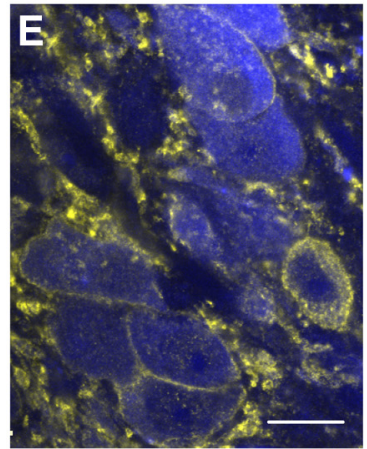

$1 \mathrm{sec}$. photostimulation at $5 \mathrm{~Hz}$
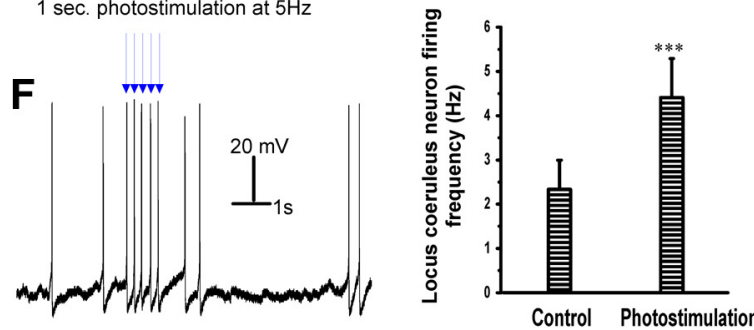

$1 \mathrm{sec}$. photostimulation at $5 \mathrm{~Hz}$

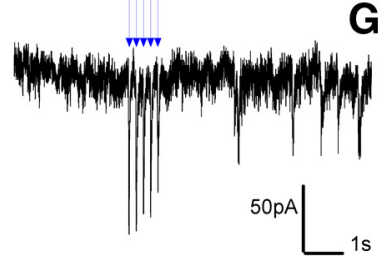

Figure 1. Selective expression ChR2 in LC neurons. In TH-Cre-ChR2-EYFP transgenic mice, strong expression of ChR2 EYFP defines the LC. The LC noradrenergic neurons express the highest levels of transgene in pontomedullary brainstem tissue. $\boldsymbol{A}$, Transverse coronal section showing that ChR2-EYFP (green) is strongly expressed within the LC located near the dorsal edge, whereas the CVNs (labeled with the retrograde fluorescent tracer XRITC, red) in the NA are localized to the ventrolateral medulla, Scale bar, $80 \mu \mathrm{m}$. $\boldsymbol{B}$, Magnified representative confocal image taken from the callout region in $\boldsymbol{A}$ from another slice of tissue, showing the ChR2-EYFP (green) expression in the cell membrane and processes of $L C$ neurons. Scale bar, $80 \mu \mathrm{m}$. $\boldsymbol{C}-\boldsymbol{E}$, Confocal images showing individual neurons, with ChR2-EYFP expression (yellow) localized to the cell membrane $(\boldsymbol{C})$ and TH immunopositivity in the cytoplasm, shown in blue $(\boldsymbol{D})$. Merged image: ChR2 expression is limited to TH immunopositive neurons, Scale bar, $9 \mu \mathrm{m}$. $\boldsymbol{F}$, Representative action potential trains recorded under current-clamp configuration from a LC neuron expressing ChR2-EYFP indicating that ChR2 activation increase firing from $2.3 \pm 0.6 \mathrm{~Hz}$ to $4.4 \pm 0.8 \mathrm{~Hz}(n=13, p<0.001)$. $\mathbf{G}$, Voltage-clamp recording of a $\mathrm{LC}$ neuron expressing ChR2-EYFP responding with a rapid excitatory inward current in response to photoactivation of ChR2. In this and all subsequent figures, ${ }^{*} p<0.05$, ${ }^{* *} p<0.01$, and ${ }^{* * *} p<0.001$.

chronous and is inhibited during each inspiration (Kunze, 1972; Spyer, 1981; Gilbey et al., 1984; Neff et al., 2003).

The association between arousal and increased heart rate is well accepted and the highly prevalent treatment for the somatic manifestation of anxiety is prevention of the accompanying tachycardia; however, the neurobiological link between the LC and parasympathetic neurons that control heart rate has not been established. Previous work has shown that tyrosine hydroxylase $\mathrm{TH}$, an essential enzyme in the generation of norepinephrine)-immunoreactive synapses innervate CVNs (Massari et al., 1998) and $\alpha_{1}$-adrenergic receptors are also present within the NA (Day et al., 1997).
However, activation of $\alpha 1, \alpha 2$, and $\beta$-adrenergic receptors elicits a wide array of often contrasting responses in CVNs (Philbin et al., 2010; Boychuk et al., 2011; Bateman et al., 2012). In this study, we test directly the hypothesis that activation of noradrenergic neurons in the LC influences CVNs using optogenetic activation of LC neurons that express channelrhodposin-2 (ChR2) and establish the pathways and receptors that can alter parasympathetic activity to the heart with increased vigilance, arousal, and stress. This work also suggests new targets and mechanisms for anti-anxiety medications such as $\alpha 1$ or $\beta 1$-adrenergic receptor antagonists or agents that act by reducing norepinephrine uptake and the subsequent release of norepinephrine from the LC synaptic terminals to elicit stable and slow heart rates during apprehension and other stressors.

\section{Materials and Methods}

Experiments. The experiments were performed in accordance with National Institutes of Health and Institutional Animal Care and Use Guidelines.

Selective expression of ChR2 in TH-containing neurons in the LC. We used the Cre/loxP recombinase system in transgenic animals to express ChR2 in LC TH cells. Briefly, the transgenic mouse Cre-responder line contains a loxP-flanked STOP cassette upstream of the ChR2-EYFP fusion gene at the Rosa 26 locus in the following cassettes: Rosa-CAGLSL-ChR2(H134R)-EYFP-WPRE-pA Strain B6 (stock \#012569; The Jackson Laboratory). These Cre-responder mice were crossbred with the Cre-driver line TH-Cre (B6; $\mathrm{Cg}-\mathrm{Tg}$ (Thcre) $1 \mathrm{Tmd} / \mathrm{J}$, stock \#008601; The Jackson Laboratory) to obtain ChR2/TH mice that express ChR2 in the LC noradrenaline neurons (Savitt et al., 2005; Madisen et al., 2012; Piñol et al., 2012). The LC-TH neurons were identified in vitro by the presence of the coexpressed EYFP.

Identification of CVNs in NA. To test the hypothesis that activation of LC neurons alters the activity of parasympathetic CVNs, the latter were labeled with the retrograde fluorescent tracer Xrhodamine-5-(and 6)-isothiocyanate (XRITC). This retrograde fluorescent tracer is taken up at the neuron's synaptic endings, is either actively transported or diffuses to the neuronal cell body, and does not alter the properties of the labeled neurons (Mendelowitz and Kunze, 1991; Mendelowitz, 1996). A right thoracotomy was performed to expose the base of the heart. XRITC $(5 \mu \mathrm{l})$ was topically applied to the epicardial surface of cardiac tissue where parasympathetic ganglia are located (Pardini et al., 1987). Animals of either sex recovered for 1-2 weeks, after which time electrophysiological experiments were conducted.

On the day of the experiment, the animals were anesthetized with a short-acting inhalation anesthetic and killed by cervical dislocation. The brains were quickly removed and placed in cold $\left(\sim 2^{\circ} \mathrm{C}\right)$ buffer containing the following (in mM): $140 \mathrm{NaCl}, 5 \mathrm{KCl}, 2 \mathrm{CaCl}_{2}, 5$ glucose, 10 HEPES, pH 7.4, equilibrated with $100 \% \mathrm{O}_{2}$ and mounted on a vibratome. The brains were mounted with their caudal ends up and their 
rostral sides attached to an agar block at an angle of 40 degrees to the plane of the blade. This angle is necessary to maintain the LC, CVNs, and the projections from the LC to CVNs in a single slice of tissue $(600-800 \mathrm{~mm}$ thick). The TH neurons in LC are identified by ChR2-eYFP expression and CVNs are identified by XRITC.

Photostimulation of LC. ChR2 is a light-gated cation channel with a peak absorption wavelength of $470 \mathrm{~nm}$. Selective optogenetic activation of the LC TH-ChR2 neurons was accomplished using a $473 \mathrm{~nm}$ laser (CrystaLaser) with short light pulses of $3 \mathrm{~ms}$ at $5 \mathrm{~Hz}$. Laser light intensity was kept constant for a given cell and was typically $10-12 \mathrm{~mW}$ for activation of ChR2 in LC neurons. Delivery of optical pulses (3 ms duration) was controlled by a digitizer (Digidata 1440A; Molecular Devices).

Electrophysiology patch-clamp techniques. Patch pipettes were filled with a solution at $\mathrm{pH} 7.3$ consisting of either $\mathrm{KCl}(150 \mathrm{~mm}), \mathrm{MgCl}_{2}$ (4 mM), EGTA (10 mM), Na-ATP (2 mM), and HEPES (10 mM) or K-gluconic acid (150 mM), HEPES (10 mM), EGTA (10 mM), $\mathrm{MgCl}_{2}(1 \mathrm{~mm})$, and $\mathrm{CaCl}_{2}$ (1 $\mathrm{mm}$ ) to isolate for inhibitory or excitatory currents, respectively. Identified CVNs were voltage clamped at a holding potential of $-80 \mathrm{mV}$. We used gabazine $(25 \mu \mathrm{M})$, strychnine $(1 \mu \mathrm{M})$, $\mathrm{D}(-)$-2amino-5-phosphopentanoic acid (AP5; $20 \mu \mathrm{M}$ ), and 6-cyano-7-nitroquinoxaline-2,3dione (CNQX; $20 \mu \mathrm{M}$ ) at concentrations sufficient to completely block activation of GABA, glycine, and glutamatergic receptors, respectively. Focal drug application was performed using a PV830 Pneumatic PicoPump pressure delivery system (WPI). Drugs were ejected from a patch pipette positioned within $30 \mu \mathrm{m}$ from the patched CVN. The maximum range of drug application has been determined previously to be $100-120 \mu \mathrm{m}$ downstream from the drug pipette and considerably less behind the drug pipette (Wang et al., 2001).

Immunohistochemistry and confocal image. For immunohistochemical and confocal imaging studies, the brainstem tissue was placed in $4 \%$ paraformaldehyde and the tissue was mounted and coverslipped with Prolong Antifade Mounting Medium (Invitrogen). To determine the specificity of the ChR2-EYFP expression, immunohistochemistry was used to colocalize TH and ChR2-eYFP expression. Slices were soaked overnight in $4 \%$ paraformaldehyde and processed for immunohistochemistry using the following primary antibodies (overnight incubation at $22-24^{\circ} \mathrm{C}$ ): rabbit anti-TH antibody (1:1000 dilution, ab112; Abcam) and chicken anti-GFP (1:1000 dilution, ab13970; Abcam). As secondary antibodies, we used goat anti-rabbit Alexa Fluor 405 and goat anti-chicken Alexa Fluor 488 (all 1:200 dilution and $4 \mathrm{~h}$ incubation at $22-24^{\circ} \mathrm{C}$; Life Technologies). The brainstem slices containing LC, CVNs, and ChR2-EYFP fibers were imaged by confocal microscopy (LSM 710; Zeiss). Stack images $(12-80 \mu \mathrm{m}$ collapsed into $2 \mathrm{D}$ images $)$ and tile scans were collected with the $20 \times$ and $63 \times$ objective of the Zeiss 710 confocal system and composed with Volocity software. For colocalization analysis, we used a $60 \mu \mathrm{m} z$-stack image of every other $100 \mu \mathrm{m}$ for offline analysis.

Data analyses. All electrophysiological data were digitized and collected via Clampex (version 10.2) and analyzed using Clampfit (version 10.2). Synaptic events were detected using MiniAnalysis version 5.6.12 (Synaptosoft). Postsynaptic currents were grouped into 13 consecutive tion (Fig. 2E).
1 second photo excitation at $5 \mathrm{~Hz}$
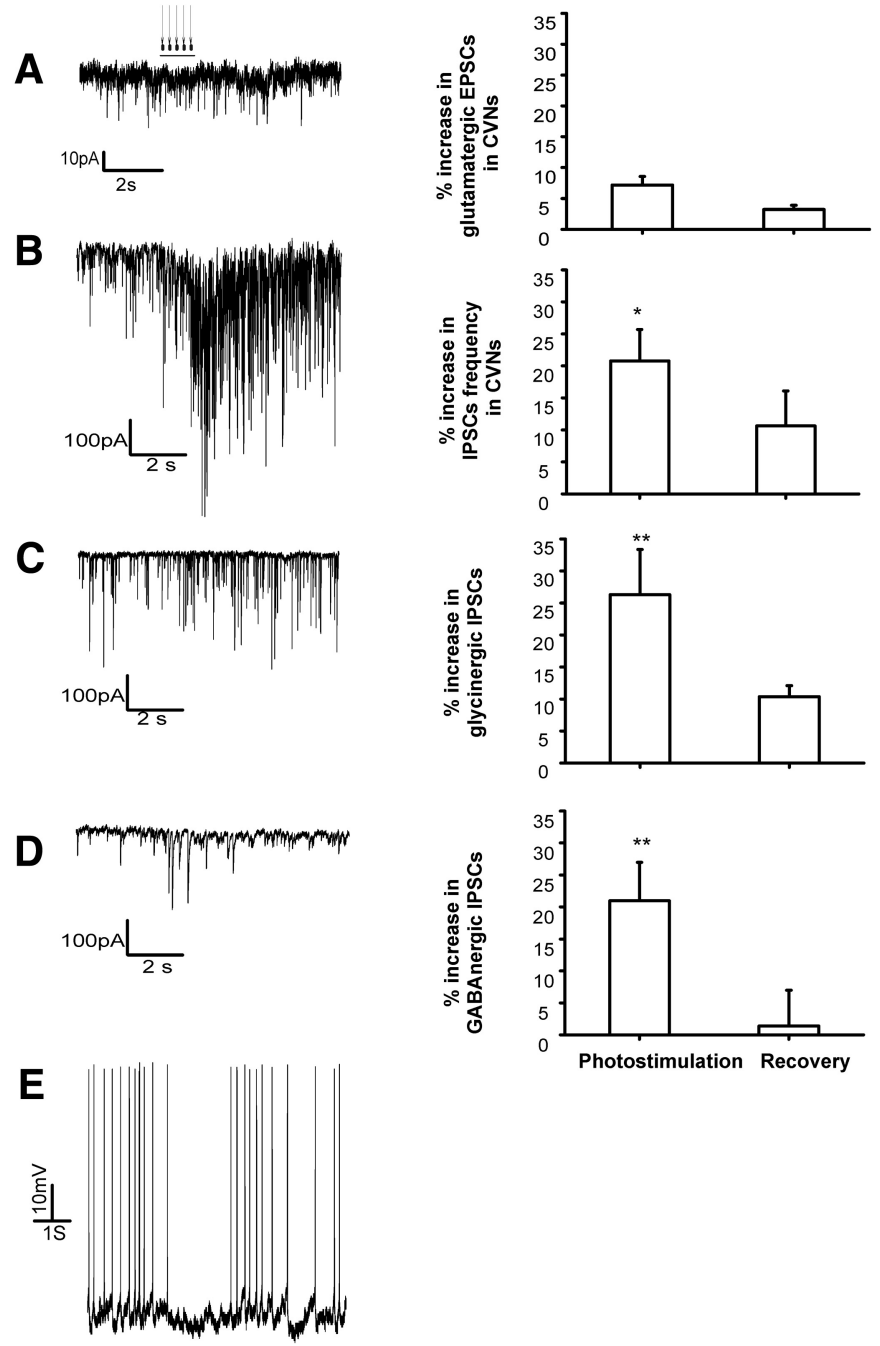

Figure 2. Optogenetic stimulation of LC ChR2-expressing neurons facilitates inhibitory neurotransmission to CVNs in the NA. Optimulation of LC neurons did not change the frequency or amplitude of EPSCS in CVNs (Fig. 2A, $n=9$ ); however, potimulation of $\mathrm{LC}$ neurons increased the frequency of IPSCS in CVNs by $21 \pm 5 \%(n=20, p=0.02 ;$ Fig. 2B). Optogenetic (Fig. $2 C, p=0.003, n=26$ ) and pattern of LC firing with optogenetic stimulation inhibited the spontaneous firing in a CVN, recorded in current-clamp configura-

$1 \mathrm{~s}$ periods. The first $2 \mathrm{~s}$ were considered the control period, followed by a $1 \mathrm{~s}$ stimulatory period and ending with a $10 \mathrm{~s}$ recovery period.

All data are presented as mean \pm SEM. Statistical comparisons were made using ANOVA with repeated measures and Newman-Keuls posttests using GraphPad Prism version 4.0, Microcal Origin version 6.1 (OriginLabs), and Microsoft Excel software for paired or unpaired Student's $t$ tests, as appropriate. $p<0.05$ indicated significant differences.

\section{Results}

Optogenetic targeting of LC neurons

To determine the specificity and extent of ChR2 expression in the LC noradrenergic neurons, we examined ChR2-EYFP expression in all catecholaminergic neurons located in the $\mathrm{A} 1 / \mathrm{C} 1, \mathrm{~A} 2 / \mathrm{C} 2$, C3, A5, and A6 regions. Although many noradrenergic fibers expressing EYFP fluorescence were detected in the brainstem, the highest level of expression in cell bodies within these cell groups occurred in the LC (A6). Punctate and robust expression was observed throughout the entire LC nucleus (Fig. 1A,B). The ChR2-EYFP expression in other regions was either weak or not 
One second photo excitation at $5 \mathrm{~Hz}$
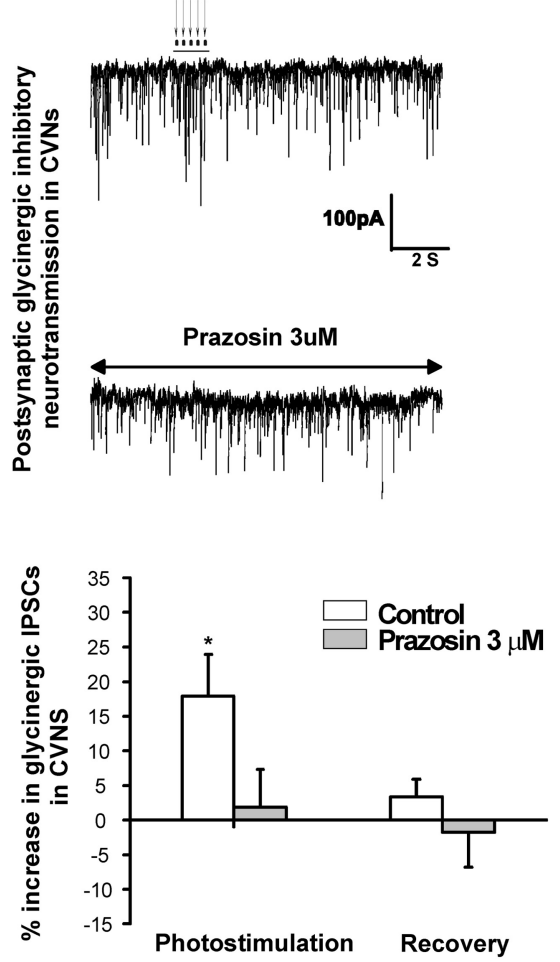

One second photo excitation at $5 \mathrm{~Hz}$
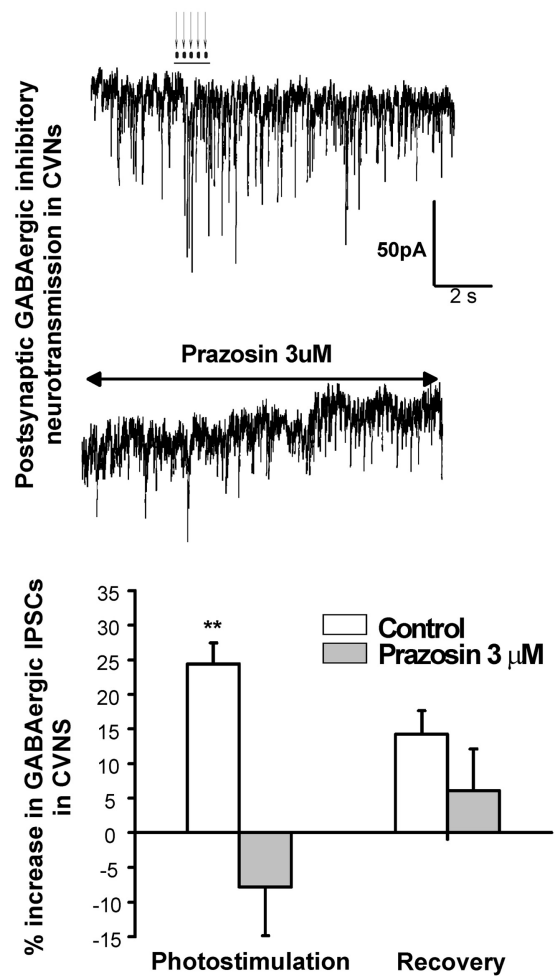

Figure 3. The $\alpha 1$-adrenergic receptor inverse agonist prazosin $(3 \mu \mathrm{m})$ blocked the evoked increase of inhibitory glycinergic and GABAergic postsynaptic inputs in CVNs. Photostimulation of LC neurons increased glycinergic IPSC frequency by $18 \pm 6 \%(n=7$, $p=0.03)$, which was prevented (1.8 $\pm 5.5 \%)$ in the presence of prazosin $(n=7, p=0.8)$. Representative traces are shown on the top left and summary data are shown on the bottom left graph. In control conditions, photostimulation of $L C$ neurons also increased GABAergic neurotransmission to CVNs by $24.4 \pm 3 \%(n=9, p=0.006)$, but in the presence of prazosin, the increase in GABAergic IPSC $s$ was abolished ( $-7.8 \pm 9 \%, n=9, p=0.8$, right traces and graph).

sufficient $(\mathrm{A} 1 / \mathrm{C} 1)$ for visualization in our in vitro tissue (A2, C3, A5). All of the LC cells expressing ChR2-EYFP were positive using immunohistochemistry for $\mathrm{TH}$ (Fig. $1 C-E$ ), whereas no ChR2-EYFP expression was found in any non-TH neurons within or near the LC.

To determine whether the expression of ChR2 in LC neurons was sufficient to alter their activity upon photoactivation, we examined the firing activity and photoactivated currents in ChR2-EYFP-positive LC neurons in both the current-clamp and voltage-clamp configurations, respectively. The activity of LC noradrenergic neurons was controlled with blue light that activated ChR2 in the LC neurons. In current-clamp configuration, photoactivation of ChR 2 consistently elicited action potentials in LC neurons with rare, if any, failures of photoactivation to elicit an action potential. Photoactivation of ChR2 in LC-ChR2 neurons increased their firing rate from an average frequency of $2.3 \pm 0.6 \mathrm{~Hz}$ to $4.4 \pm 0.8 \mathrm{~Hz}(n=13, p<0.001$; Fig. $1 F)$. In voltage-clamp configuration, photoexcitation of ChR2 in LC neurons with a short pulse of 3 ms elicited rapid excitatory inward currents with a peak amplitude of $-146 \pm 47 \mathrm{pA}(n=13$ cells; Fig. $1 G$ ). These results demonstrate that the expression of ChR2 is sufficient, when photoactivated, to generate action potential firing in LC noradrenergic neurons.

Optogenetic stimulation of LC noradrenergic neurons increases the inhibitory synaptic pathway to cardiac vagal neurons in the nucleus ambiguus

To determine whether optogenetic activation of LC neurons alters neurotransmission to CVNs, we examined separately

changes in excitatory and inhibitory synaptic events in CVNs upon photoactivation of LC neurons. To isolate excitatory synaptic events, the $\mathrm{GABA}_{\mathrm{A}}$ receptor antagonist gabazine $(25 \mu \mathrm{M})$ and the glycine receptor antagonist strychnine $(1 \mu \mathrm{M})$ were included in the perfusate. To isolate inhibitory synaptic events, the glutamatergic receptor antagonists AP5 $(20 \mu \mathrm{M})$ and CNQX $(20 \mu \mathrm{M})$ were included in the perfusate.

Optogenetic stimulation of LC neurons did not change the frequency or amplitude of EPSCs in CVNs $(n=9$; Fig. $2 A)$ and there was no change in holding current in CVNs upon LC photostimulation. However, photostimulation of LC neurons increased the frequency of IPSCs in CVNs by $21 \pm 5 \%(n=20, p=0.02$; Fig. $2 B$ ) from an average of $7.6 \pm 0.9 \mathrm{~Hz}$ to $8.8 \pm 1 \mathrm{~Hz}$ (during stimulation, $p=$ 0.0003, $n=20$ ). To determine whether both GABAergic and glycinergic IPSCs in CVNs were facilitated upon LC photostimulation, GABAergic and glycinergic IPSCs were isolated for study. To isolate GABAergic events, the perfusate contained strychnine $(1 \mu \mathrm{M})$, AP5 $(20 \mu \mathrm{M})$, and CNQX $(20 \mu \mathrm{M})$. To isolate for glycinergic IPSCs, the perfusate contained gabazine $(25 \mu \mathrm{M})$, AP5 $(20 \mu \mathrm{M})$, and CNQX $(20 \mu \mathrm{M})$. Optogenetic activation of LC neurons increased the frequency of isolated inhibitory glycinergic IPSCs in CVNs by $27 \pm 8 \%(p=0.003, n=26$; Fig. $2 C)$ and augmented isolated GABAergic IPSCs in CVNs by $21 \pm 5 \%(p=0.001, n=$ 26; Fig. 2D), respectively.

In current-clamp configuration, as described previously (Mendelowitz, 1996), most cardiac vagal neurons are silent and do not fire spontaneously. However, three of nine CVNs recorded in current-clamp configuration did have occasional spontaneous action potentials. In these CVNs that fired spontaneously, optogenetic stimulation of the LC inhibited their firing (Fig. 2E).

\section{Receptors that mediate the responses in CVNs upon optogenetic stimulation of the LC}

To identify the receptors that mediate the increase of inhibitory neurotransmission to CVNs upon photoactivation of the LC noradrenaline neurons, we examined the LC-elicited changes in IPSC frequencies in additional experiments in the presence of the $\alpha 1$-adrenergic receptor inverse agonist prazo$\sin (3 \mu \mathrm{M})$, the $\alpha 2$-adrenergic receptor antagonist yohimbine $(2 \mu \mathrm{M})$, and the $\beta 1$-adrenergic receptor antagonist atenolol (2 $\mu \mathrm{M})$, respectively.

The $\alpha 1$-adrenergic receptor inverse agonist prazosin $(3 \mu \mathrm{M})$ blocked the optogenetic evoked enhancement of inhibitory glycinergic and GABAergic postsynaptic inputs in CVNs (Fig. 3). The photostimulation of LC neurons increased glycinergic IPSC frequency by $18 \pm 6 \%(n=7, p=0.03)$, from an average of $4.4 \pm 0.8 \mathrm{~Hz}$ to $5.2 \pm 0.9 \mathrm{~Hz}$, which was prevented $(1.8 \pm$ $5.5 \%)$ in the presence of prazosin $(n=7, p=0.8$; control and photostimulation-evoked glycinergic IPSC frequencies were 
$3.4 \pm 0.7 \mathrm{~Hz}$ and $3.5 \pm 0.8 \mathrm{~Hz}$, respectively; Fig. 3, left traces and graph). In control conditions, photostimulation of LC neurons also increased GABAergic IPSC frequency to CVNs, from control of $2.0 \pm 0.4 \mathrm{~Hz}$ to $2.5 \pm 0.4 \mathrm{~Hz}$, an increase of $24.4 \pm 3 \%(n=9, p=0.006)$; however, in the presence of prazosin, the increase in GABAergic IPSCs was abolished $(-7.8 \pm$ $9 \%$, control $1.3 \pm 0.3 \mathrm{~Hz}$ to $1.2 \pm 0.3 \mathrm{~Hz}$ during photostimulation; $n=9, p=0.8$; Fig. 3, right traces and graph).

In contrast, yohimbine, an $\alpha-2$ antagonist, did not significantly alter the increase in inhibitory GABAergic or glycinergic neurotransmission to CVNs upon LC photoactivation (Fig. 4). The photostimulation of LC neurons increased glycinergic IPSC frequency from $2.1 \pm 0.4 \mathrm{~Hz}$ to $2.5 \pm 0.4 \mathrm{~Hz}$, an increase of $19 \pm 5 \%(n=10, p=0.03)$, in control and by $19 \pm 4 \%$ in the presence of yohimbine (from $1.3 \pm 0.3 \mathrm{~Hz}$ to $1.6 \pm 0.4 \mathrm{~Hz}$, $n=10, p=0.04$, left traces and graph). In control conditions, photostimulation of LC neurons also increased GABAergic neurotransmission to CVNs by $30 \pm 7 \%$, from an average of $1.7 \pm 0.4 \mathrm{~Hz}$ to $2.3 \pm$ $0.7 \mathrm{~Hz}(n=9, p=0.03)$. In the presence of yohimbine $(2 \mu \mathrm{M})$, the increase in GABAergic IPSCs was maintained from $1.5 \pm 0.3 \mathrm{~Hz}$ to $2.0 \pm 0.4 \mathrm{~Hz}(27.6 \pm 8 \%$, $n=9, p=0.02$, right traces and graph).

The selective $\beta 1$ receptor antagonist atenolol $(2 \mu \mathrm{M})$ did not alter the increase in inhibitory GABAergic neurotransmission to CVNs, but did prevent the increase in glycinergic IPSCs in CVNs (Fig. 5). The photostimulation of LC neurons increased glycinergic neurotransmission to CVNs by $21.7 \pm 7 \%$, from an average of $3.2 \pm 0.6 \mathrm{~Hz}$ to $4.0 \pm 0.7 \mathrm{~Hz}(n=10, p=0.016$, left trace and graph). This increase was prevented by atenolol from $2.5 \pm 0.3 \mathrm{~Hz}$ to $2.4 \pm 0.3 \mathrm{~Hz}(-3.4 \pm 4 \%, p=0.4, n=10$, left second trace and bottom graph). However, atenolol did not alter the increase in inhibitory GABAergic neurotransmission to CVNs. The photostimulation of LC neurons increased GABAergic neurotransmission to CVNs by $18.6 \pm 5 \%$ from $4.7 \pm 0.7$ to $5.5 \pm 0.7 \mathrm{~Hz}(n=9, p=0.02$; control, top right trace). In the presence of atenolol, GABAergic neurotransmission to CVNs increased by $21 \pm 8 \%$ from $2.9 \pm 0.6$ to $3.5 \pm 0.5 \mathrm{~Hz}(n=9, p=$ 0.03 ; Fig. 5 , bottom trace and graph).

\section{Discussion}

The LC noradrenergic system enhances arousal and vigilance, in part via activation of $\alpha$ and $\beta$-adrenergic receptors located within multiple subcortical structures (Berridge, 2008; Schmeichel and Berridge, 2013). Inhibition of $\alpha$ - and $\beta$-adrenergic receptors have been found to significantly reduce symptoms of the fight-or-flight response in anxiety disorders and has been used clinically to assist anxious individuals to focus on the task at hand and to reduce tachycardias and tremors (Tyrer, 1992; Schneier, 2006). However, the mechanism by which $\alpha$ and $\beta$ blockers provide their beneficial effects were not known. This study provides a basis for these findings and demonstrates that
LC noradrenergic neurons depress the activity of cardioinhibitory parasympathetic cardiac vagal neurons by polysynaptic activation of inhibitory neurotransmission within this brainstem autonomic and attentiveness circuitry. Furthermore, this network interaction is dependent upon activation of $\alpha 1$ receptors that mediate increases in both GABAergic and glycinergic neurotransmission, whereas $\beta 1$ receptor activation increases glycinergic, but not GABAergic, neurotransmission to CVNs upon LC photoactivation.

LC noradrenergic neurons are responsible for stimulating behavioral arousal and alertness (Aston-Jones and Bloom, 1981b; Aston-Jones, 2005; Aston-Jones and Cohen, 2005a, 2005b) and maintaining cognitive performance, motor function (Carter et al., 2010), autonomic regulation (Yao et al., 1999), and stress responses while awake (McCarley and Hobson, 1975; AstonJones and Bloom, 1981a). Unlike most nuclei in the CNS, which are composed of principal neurons that project to other areas and interneurons that serve to integrate information among afferents, the noradrenergic LC nucleus is composed almost entirely of noradrenergic principal neurons. Changes in tonic and stimulusinduced activity in the LC noradrenergic brainstem nucleus are tightly correlated with fluctuations in behavioral performance and stress (Morilak et al., 1987a, 1987c, 1987b). LC neurons exhibit both phasic and tonic patterns of activity. Phasic LC activation is driven by the outcome of task-related decision processes and is proposed to facilitate ensuing behaviors and to help opti- 
One second photo excitation at $5 \mathrm{~Hz}$
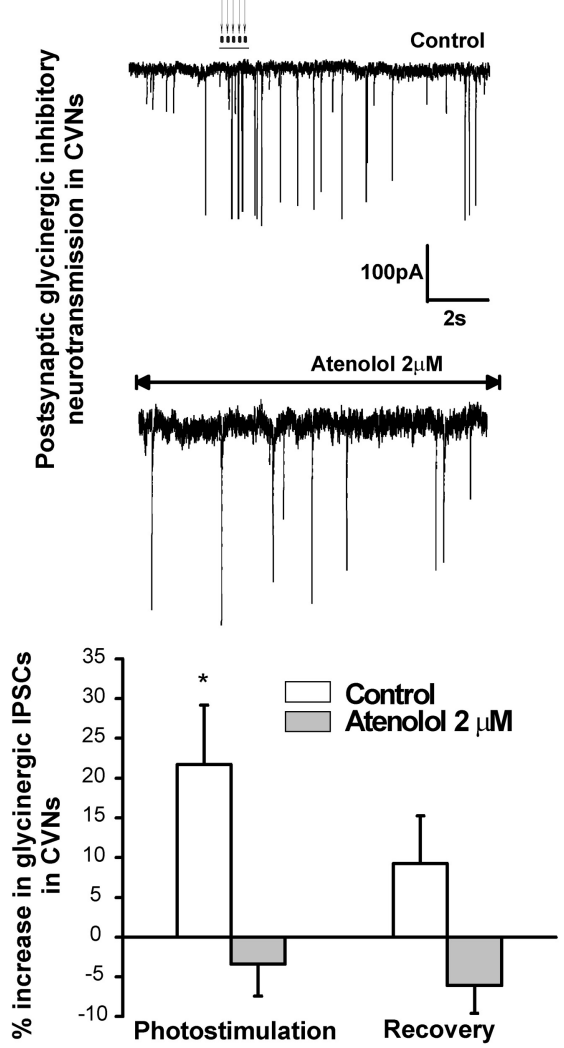

\section{One second photo excitation at $5 \mathrm{~Hz}$}
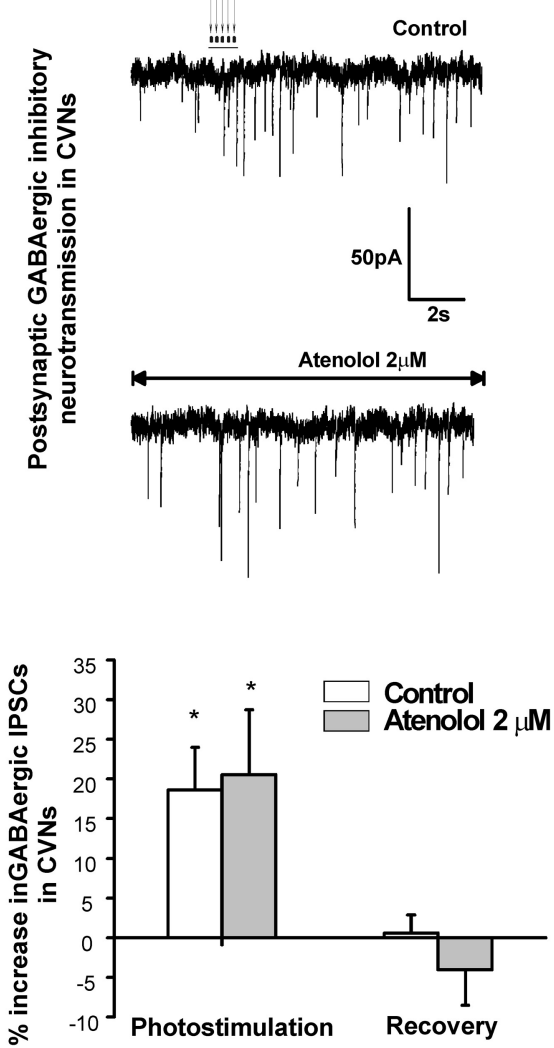

Figure 5. The selective $\beta 1$-adrenergic receptor antagonist atenolol $(2 \mu \mathrm{m})$ prevented the increase in glycinergic, but not GABAergic, IPSCs in CVNs. The photostimulation of $\mathrm{LC}$ neurons increased glycinergic neurotransmission to CVNs by $21.7 \pm$ $7 \%(n=10, p=0.016)$, but this increase was prevented by atenolol $(-3.4 \pm 4 \%, p=0.4, n=10)$. Representative traces are shown on the top left and summary data on the bottom left graph. However, atenolol did not alter the increase in inhibitory GABAergic neurotransmission to CVNs. The photostimulation of $\mathrm{LC}$ neurons increased GABAergic neurotransmission to CVNs by $18.6 \pm 5 \%(n=9, p=0.02$; in control, top right trace and right graph). In the presence of atenolol, GABAergic neurotransmission to CVNs increased by $21 \pm 8 \%(n=9, p=0.03$, bottom right trace and right graph) upon photoactivation of $\mathrm{LC}$ neurons.

mize task performance. This phasic LC activation varies with vigilance and attention (Aston-Jones et al., 1991a). When focus on a task wanes, LC neurons alter their activity from a phasic to a tonic firing pattern that is associated with disengagement from the current task and a search for alternative behaviors.

Previous in vivo studies using electrical stimulation (Gurtu et al., 1984) or pharmacological approaches (Harris and Fitzgerald, 1991; Yao et al., 1999) have shown that stimulation of LC increases heart rate and blood pressure (Hwang et al., 1998; Grindstaff et al., 2000), indicating that noradrenergic neurons in the LC participate in central autonomic regulation during arousal and/or wakefulness. Indeed, ablation of the anterior region of the LC induces behavioral state-dependent bradycardia and significantly reduces the phasic tachycardia seen during REM sleep (Liesiene et al., 1981).

Recent anatomical, physiological, pharmacological, and animal behavioral experiments have shown that firing of neurons in the LC and subsequent activation of $\alpha$ - and $\beta$-adrenergic receptors play a major role in the responses to stress and anxiety (Aston-Jones et al., 1991b; Abbott et al., 2012). Specifically, $\beta$-adrenergic receptor blockade, but not cortisol synthesis inhibition, diminished the increase of noradrenergic activation during acute vigilant stress (Hermans et al., 2011). Our results show that the selective $\beta_{1}$-adrenergic receptor antagonist atenolol, at a clinical relevant concentration, prevented the LC-induced increase in the frequency of inhibitory glycinergic, but not GABAergic, synaptic events in CVNs. The $\alpha 1$ adrenergic receptor inverse agonist prazosin $(3 \mu \mathrm{M})$ blocked LC-elicited enhancement of both inhibitory glycinergic and GABAergic postsynaptic inputs in CVNs. Preventing the activation of these adrenergic receptors in this brainstem network would enable parasympathetic CVNs to remain active, thus averting the increases in heart rate and risks of tachycardia that usually occur in stress and anxiety. In a previous study, our group identified four specific areas that contain GABAergic cells that project to CVNs; three of the four loci are in close apposition to the CVNs $(200 \mathrm{~mm}$ medial, $400 \mathrm{~mm}$ medial, $200 \mathrm{~mm}$ ventral to the CVNs in the NA) and the fourth loci is in the nucleus of the solitary track region (1200 mm dorsal and $1000 \mathrm{~mm}$ medial to the CVNs in the NA; Frank et al., 2009). The three populations of GABAergic neurons close to the NA were retained in the brainstem slice used in this study and are the probable source of the GABAergic neurons that are activated by LC stimulation and project to CVNs. These sites of action in the brainstem are likely one important target, but not the only possible target, for $\alpha 1$ and $\beta 1$ receptor blockers to treat anxiety disorders with cardiovascular complications. $\beta 1$ receptor blockers have also been proposed as a treatment for anxiety disorders, acting by blocking activation of peripheral adrenergic receptors, such as those in the heart, by the high endogenous levels of catecholamines that are in the circulation during stress and anxiety (Baker et al., 2011).

In conclusion, the LC noradrenergic system is critical for many biological functions, particularly the responses to heightened attention, fear, and anxiety. Perturbations in LC function are thought to be involved in many anxiety-related disorders, including depression, panic disorder, Parkinson's disease, and anxiety. Medications including $\beta$-adrenergic blockers, norepinephrine reuptake inhibitors, serotonin-norepinephrine reuptake inhibitors, and norepinephrine-dopamine reuptake inhibitors are believed to show efficacy by acting upon LC neurons or their targets. This study demonstrates LC noradrenergic neurons likely increase heart rate and the adverse risks associated with tachycardia by depressing the activity of cardioinhibitory parasympathetic cardiac vagal neurons. This network modulation occurs via a polysynaptic activation of inhibitory neurotransmission that is dependent upon activation of $\alpha 1$ and $\beta 1$ receptors at autonomic sites precedent to CVNs in the brainstem. These are prospective targets by which antagonists for $\alpha 1$ and/or $\beta 1$ receptors can prevent increases in heart rate during periods of panic, anxiety, and heightened vigilance. 


\section{References}

Abbott SB, Kanbar R, Bochorishvili G, Coates MB, Stornetta RL, Guyenet PG (2012) C1 neurons excite locus coeruleus and A5 noradrenergic neurons along with sympathetic outflow in rats. J Physiol 590:2897-2915. CrossRef Medline

Armour JA (2008) Potential clinical relevance of the 'little brain' on the mammalian heart. Exp Physiol 93:165-176. CrossRef Medline

Aston-Jones G (2005) Brain structures and receptors involved in alertness. Sleep Med 6:S3-S7. CrossRef Medline

Aston-Jones G, Bloom FE (1981a) Norepinephrine-containing locus coeruleus neurons in behaving rats exhibit pronounced responses to nonnoxious environmental stimuli. J Neurosci 1:887-900. Medline

Aston-Jones G, Bloom FE (1981b) Activity of norepinephrine-containing locus coeruleus neurons in behaving rats anticipates fluctuations in the sleep-waking cycle. J Neurosci 1:876-886. Medline

Aston-Jones G, Cohen JD (2005a) Adaptive gain and the role of the locus coeruleus-norepinephrine system in optimal performance. J Comp Neurol 493:99-110. CrossRef Medline

Aston-Jones G, Cohen JD (2005b) An integrative theory of locus coeruleusnorepinephrine function: adaptive gain and optimal performance. Annu Rev Neurosci 28:403-450. CrossRef Medline

Aston-Jones G, Chiang C, Alexinsky T (1991a) Discharge of noradrenergic locus coeruleus neurons in behaving rats and monkeys suggests a role in vigilance. Prog Brain Res 88:501-520. CrossRef Medline

Aston-Jones G, Shipley MT, Chouvet G, Ennis M, van Bockstaele E, Pieribone V, Shiekhattar R, Akaoka H, Drolet G, Astier B (1991b) Afferent regulation of locus coeruleus neurons: anatomy, physiology and pharmacology. Prog Brain Res 88:47-75. CrossRef Medline

Baker JG, Hill SJ, Summers RJ (2011) Evolution of beta-blockers: from antianginal drugs to ligand-directed signalling. Trends Pharmacol Sci 32:227234. CrossRef Medline

Bateman RJ, Boychuk CR, Philbin KE, Mendelowitz D (2012) Beta adrenergic receptor modulation of neurotransmission to cardiac vagal neurons in the nucleus ambiguus. Neuroscience 210:58-66. CrossRef Medline

Berridge CW (2008) Noradrenergic modulation of arousal. Brain Res Rev 58:1-17. CrossRef Medline

Boychuk CR, Bateman RJ, Philbin KE, Mendelowitz D (2011) alpha1adrenergic receptors facilitate inhibitory neurotransmission to cardiac vagal neurons in the nucleus ambiguus. Neuroscience 193:154-161. CrossRef Medline

Carter ME, Yizhar O, Chikahisa S, Nguyen H, Adamantidis A, Nishino S, Deisseroth K, de Lecea L (2010) Tuning arousal with optogenetic modulation of locus coeruleus neurons. Nat Neurosci 13:1526-1533. CrossRef Medline

Cheng Z, Powley TL (2000) Nucleus ambiguus projections to cardiac ganglia of rat atria: an anterograde tracing study. J Comp Neurol 424:588606. CrossRef Medline

Cheng Z, Powley TL, Schwaber JS, Doyle FJ 3rd (1999) Projections of the dorsal motor nucleus of the vagus to cardiac ganglia of rat atria: an anterograde tracing study. J Comp Neurol 410:320-341. CrossRef Medline

Day HE, Campeau S, Watson SJ Jr, Akil H (1997) Distribution of alpha 1a-, alpha 1b- and alpha 1d-adrenergic receptor mRNA in the rat brain and spinal cord. J Chem Neuroanat 13:115-139. CrossRef Medline

España RA, Scammell TE (2011) Sleep neurobiology from a clinical perspective. Sleep 34:845-858. CrossRef Medline

Frank JG, Jameson HS, Gorini C, Mendelowitz D (2009) Mapping and identification of GABAergic neurons in transgenic mice projecting to cardiac vagal neurons in the nucleus ambiguus using photo-uncaging. J Neurophysiol 101:1755-1760. CrossRef Medline

Gilbey MP, Jordan D, Richter DW, Spyer KM (1984) Synaptic mechanisms involved in the inspiratory modulation of vagal cardio-inhibitory neurones in the cat. J Physiol 356:65-78. Medline

Goldstein M, Fuxe K, Hökfelt T, Joh TH (1971) Immunohistochemical studies on phenylethanolamine- $N$-methyltransferase, dopa-decarboxylase and dopamine-hydroxylase. Experientia 27:951-952. CrossRef Medline

Grindstaff RJ, Grindstaff RR, Sullivan MJ, Cunningham JT (2000) Role of the locus ceruleus in baroreceptor regulation of supraoptic vasopressin neurons in the rat. Am J Physiol Regul Integr Comp Physiol 279:R306R319. Medline

Gurtu S, Pant KK, Sinha JN, Bhargava KP (1984) An investigation into the mechanism of cardiovascular responses elicited by electrical stimulation of locus coeruleus and subcoeruleus in the cat. Brain Res 301:59-64. CrossRef Medline

Harris GC, Fitzgerald RD (1991) Locus coeruleus involvement in the learning of classically conditioned bradycardia. J Neurosci 11:2314-2320. Medline

Hermans EJ, van Marle HJ, Ossewaarde L, Henckens MJ, Qin S, van Kesteren MT, Schoots VC, Cousijn H, Rijpkema M, Oostenveld R, Fernández G (2011) Stress-related noradrenergic activity prompts large-scale neural network reconfiguration. Science 334:1151-1153. CrossRef Medline

Hwang KR, Chan SH, Chan JY (1998) Noradrenergic neurotransmission at PVN in locus ceruleus-induced baroreflex suppression in rats. Am J Physiol 274:H1284-H1292. Medline

Kunze DL (1972) Reflex discharge patterns of cardiac vagal efferent fibres. J Physiol 222:1-15. Medline

Liesiene V, Adrien J, Benoit O (1981) Effects of locus coeruleus lesions on heart rate during sleep in the cat. Arch Ital Biol 119:125-138. Medline

Madisen L, Mao T, Koch H, Zhuo JM, Berenyi A, Fujisawa S, Hsu YW, Garcia AJ 3rd, Gu X, Zanella S, Kidney J, Gu H, Mao Y, Hooks BM, Boyden ES, Buzsáki G, Ramirez JM, Jones AR, Svoboda K, Han X, Turner EE, Zeng H (2012) A toolbox of Cre-dependent optogenetic transgenic mice for light-induced activation and silencing. Nat Neurosci 15:793-802. CrossRef Medline

Massari VJ, Dickerson LW, Gray AL, Lauenstein JM, Blinder KJ, Newsome JT, Rodak DJ, Fleming TJ, Gatti PJ, Gillis RA (1998) Neural control of left ventricular contractility in the dog heart: synaptic interactions of negative inotropic vagal preganglionic neurons in the nucleus ambiguus with tyrosine hydroxylase immunoreactive terminals. Brain Res 802:205-220. CrossRef Medline

McCarley RW, Hobson JA (1975) Neuronal excitability modulation over the sleep cycle: a structural and mathematical model. Science 189:58-60. CrossRef Medline

Mendelowitz D (1996) Firing properties of identified parasympathetic cardiac neurons in nucleus ambiguus. Am J Physiol 271:H2609-H2614. Medline

Mendelowitz D, Kunze DL (1991) Identification and dissociation of cardiovascular neurons from the medulla for patch clamp analysis. Neurosci Lett 132:217-221. CrossRef Medline

Morilak DA, Fornal CA, Jacobs BL (1987a) Effects of physiological manipulations on locus coeruleus neuronal activity in freely moving cats. II. Cardiovascular challenge. Brain Res 422:24-31. CrossRef Medline

Morilak DA, Fornal CA, Jacobs BL (1987b) Effects of physiological manipulations on locus coeruleus neuronal activity in freely moving cats. III. Glucoregulatory challenge. Brain Res 422:32-39. CrossRef Medline

Morilak DA, Fornal CA, Jacobs BL (1987c) Effects of physiological manipulations on locus coeruleus neuronal activity in freely moving cats. I. Thermoregulatory challenge. Brain Res 422:17-23. CrossRef Medline

Neff RA, Wang J, Baxi S, Evans C, Mendelowitz D (2003) Respiratory sinus arrhythmia: endogenous activation of nicotinic receptors mediates respiratory modulation of brainstem cardioinhibitory parasympathetic neurons. Circ Res 93:565-572. CrossRef Medline

Nygren LG, Olson L (1977) A new major projection from locus coeruleus: the main source of noradrenergic nerve terminals in the ventral and dorsal columns of the spinal cord. Brain Res 132:85-93. CrossRef Medline

Olson L, Fuxe K (1971) On the projections from the locus coeruleus noradrealine neurons: the cerebellar innervation. Brain Res 28:165-171. CrossRef Medline

Pardini BJ, Patel KP, Schmid PG, Lund DD (1987) Location, distribution and projections of intracardiac ganglion cells in the rat. J Auton Nerv Syst 20:91-101. CrossRef Medline

Philbin KE, Bateman RJ, Mendelowitz D (2010) Clonidine, an alpha2receptor agonist, diminishes GABAergic neurotransmission to cardiac vagal neurons in the nucleus ambiguus. Brain Res 1347:65-70. CrossRef Medline

Piñol RA, Bateman R, Mendelowitz D (2012) Optogenetic approaches to characterize the long-range synaptic pathways from the hypothalamus to brain stem autonomic nuclei. J Neurosci Methods 210:238-246. CrossRef Medline

Savitt JM, Jang SS, Mu W, Dawson VL, Dawson TM (2005) Bcl-x is required for proper development of the mouse substantia nigra. J Neurosci 25: 6721-6728. CrossRef Medline

Schmeichel BE, Berridge CW (2013) Wake-promoting actions of noradren- 
ergic alpha1 - and beta-receptors within the lateral hypothalamic area. Eur J Neurosci 37:891-900. CrossRef Medline

Schneier FR (2006) Clinical practice-social anxiety disorder. N Engl J Med 355:1029-1036. CrossRef Medline

Spyer KM (1981) Neural organisation and control of the baroreceptor reflex. Rev Physiol Biochem Pharmacol 88:24-124. Medline

Standish A, Enquist LW, Escardo JA, Schwaber JS (1995) Central neuronal circuit innervating the rat heart defined by transneuronal transport of pseudorabies virus. J Neurosci 15:1998-2012. Medline

Toscani L, Gangemi PF, Parigi A, Silipo R, Ragghianti P, Sirabella E, Morelli M, Bagnoli L, Vergassola R, Zaccara G (1996) Human heart rate variability and sleep stages. Ital J Neurol Sci 17:437-439. CrossRef Medline

Tyrer P (1992) Anxiolytics not acting at the benzodiazepine receptor: beta blockers. Prog Neuropsychopharmacol Biol Psychiatry 16:17-26. CrossRef Medline

Verrier RL, Lau TR, Wallooppillai U, Quattrochi J, Nearing BD, Moreno R, Hobson JA (1998) Primary vagally mediated decelerations in heart rate during tonic rapid eye movement sleep in cats. Am J Physiol 274:R1136R1141. Medline

Wang J, Irnaten M, Neff RA, Venkatesan P, Evans C, Loewy AD, Mettenleiter TC, Mendelowitz D (2001) Synaptic and neurotransmitter activation of cardiac vagal neurons in the nucleus ambiguus. Ann N Y Acad Sci 940: 237-246. CrossRef Medline

Yao ST, Finkelstein DI, Lawrence AJ (1999) Nitrergic stimulation of the locus coeruleus modulates blood pressure and heart rate in the anaesthetized rat. Neuroscience 91:621-629. CrossRef Medline 